\title{
Burn wound healing properties of asiaticoside and madecassoside
}

\author{
QIANG HOU* ${ }^{*}$ MING LI*, YAN-HUA LU, DONG-HONG LIU and CHENG-CUN LI \\ Department of Burns, Affiliated Hospital of Taishan Medical College, Tai'an, Shandong 271000, P.R. China
}

Received November 23, 2014; Accepted March 17, 2016

DOI: $10.3892 / \mathrm{etm} .2016 .3459$

\begin{abstract}
The healing of burn wounds has been widely characterized to be highly intricate, involving processes such as neo-vascularization, granulation, re-epithelialization, inflammation and wound contraction. Various therapies are available for the management of burn wounds; however, a truly effective therapeutic strategy has yet to be identified due to safety issues. The aim of the present study was to assess and confirm the burn wound healing properties of the compounds asiaticoside (AE) and madecassoside (MA), which are found in the herb Centella asiatica. The cytotoxic nature of the AE and MA were inspected and were confirmed to be non-toxic up to $500 \mathrm{ppm}$. The compounds AE and MA increased monocyte chemoattractant protein-1 production, but caused no significant effect on vascular endothelial growth factor production. In addition, an in vivo animal burn model was employed to represent the features of burn wound healing. Hence, the present results warrant the further investigation of $C$. asiatica extracts for use in burn healing.
\end{abstract}

\section{Introduction}

Despite the technological advancements of recent years, the utilization of herbal medicine as an alternative approach to the treatment of burn wounds remains limited (1). This is due to issues involving resistance, side effects and the use of negative pressure wound devices, which affect the healing outcome (2). Among the widely available medicinal herbs, it has been previously reported that extracts from Centella asiatica (L.) Urban, which is also known as Asiatic Penny-wort, possesses properties able to cure certain injuries, including ulcerous skin abnormalities, burns, duodenal and stomach ulcers. In addition, $C$. asiatica extracts have been applied to the treatment of lupus, scleroderma, leprosy and diseases of the veins (3). The

Correspondence to: Dr Cheng-Cun Li, Department of Burns, Affiliated Hospital of Taishan Medical College, 706 Taishan Street, Tai'an, Shandong 271000, P.R. China

E-mail: chencunli2324@gmail.com

*Contributed equally

Key words: asiaticoside, madecassoside, burn wound, in vivo, cytotoxicity mechanisms of action of this extract are speculated to include the synthesis of collagen and stimulation of extracellular matrix accumulation $(4,5)$. There are numerous active compounds in C. asiatica, including several triterpenoid saponins; madecassoside (MA), asiatic acid and asiaticoside (AE) (6).

A previous study investigated the efficacy of using the active compound trisaccharide triterpene in wound healing, and demonstrated that it was able to increase the levels of antioxidants in a rat model of initial stage excision-type cutaneous wounds (7). Furthermore, it has been reported that procollagen mRNA types I and III isoforms and their protein production, as well as the proliferation of human dermal fibroblasts, are increased with exposure to $C$. asiatica (8). Alternatively, $C$. asiatica has been utilized as a complementary medicine that can be administered orally or topically to stimulate wound recovery (9).

Furthermore, the compound MA, which is found in C. asiatica, has been reported to stimulate the expression of collagen and speculated to possess immunomodulatory properties (10). Notably, Haftek et al (11) conducted a double-blind, randomized clinical investigation, which indicated substantial improvement in the clinical score for suppleness, firmness, wrinkles, roughness as well as skin hydration with the use of C. asiatica.

In addition, when the extract is ingested orally, the active compounds present have been reported to improve the regeneration of nerve tissue apart from stimulating neurite elongation in an in vitro setting (12). Further to this, the extract has similarly demonstrated the ability to increase neurite formation, particularly in the SH-SY5Y human cell line with the addition of neuronal factors $(13,14)$. A predominant factor involved in functional recovery following burn wounds is axonal regeneration, and this was also noted with presence of non-polar fraction (GKF4) (15). Normally, in cases of burn injuries, the first line of defense includes a well-orchestrated, complex wound healing process $(16,17)$. As a result of the directly afflicted burn injury, the central area of coagulation is comprised of tissue as well as cell necrosis (18). Monocyte-derived macrophages and neutrophils are then attracted to the site as a response to the selection of cytokines and chemoattractants released by platelets in the hemostatic clot (19).

Furthermore, it should be noted that burn wound healing requires a series of intricate phases which include neovascularization, re-epithelialization, inflammation, granulation, neovascularization and wound contraction $(20,21)$. Throughout this process, a selection of bio-messengers are thus activated 
including, cytokines, liver and kidney damage biomarkers and antioxidants (22). Burn wounds are normally characterized as tissue injury due to external causes such as chemicals, radiation, heat and electricity (23). As a result, the outcome of burn wounds generated may be further grouped into superficial (first degree), partial thickness (second degree) or full-thickness (third degree), primarily based upon the depth of the wound (24). Wound healing following burns involves a multitude of processes, including inflammation that disrupts blood vessels and induces 'leakage' of blood constituents into the target area which then stimulate re-epithelialization (25). Subsequently, granulation tissue comprised of macrophages and fibroblasts is formed and this complex tissue is responsible for extracellular matrix recovery, neo-vascularization towards the target area in addition to the mitogenic stimulation and migration of cells of endothelial origin (26). Finally, contraction of the wound occurs as a result of communication between extra-cellular matrix cells as well as cytokines (27). Due to the potential healing properties of medicinal plants, alkaloids such as flavonoids, essential oils, fatty acids, tannins, saponins, terpenoids and phenolic compounds, may be useful in improving the healing process. Furthermore, medicinal plants are renowned for their availability, cost effectiveness and an association with fewer side effects compared with FDA approved drugs (28). Thus, substantial interest exists globally, concerning the identification and isolation of the active components from therapeutic plants which may promote would healing $(29,30)$.

Thus, the aim of the present study was to investigate the potential for using $\mathrm{AE}$ and MA as burn healing agents and their effects in vivo and in vitro.

\section{Materials and methods}

Chemicals and reagents. Compounds $\mathrm{AE}$ (molecular weight, $959.12 \mathrm{~g} / \mathrm{mol}$; molecular formula, $\mathrm{C}_{48} \mathrm{H}_{78} \mathrm{O}_{19}$ ) and MA (molecular weight, $975.12 \mathrm{~g} / \mathrm{mol}$; molecular formula, $\mathrm{C}_{48} \mathrm{H}_{78} \mathrm{O}_{20}$ ) were obtained from Sigma-Aldrich (Shanghai, China). RPMI-1640 medium and Dulbecco's modified Eagle's medium, were acquired from Sigma-Aldrich China, Inc., (Shanghai, China). Supplementary agents, including antibiotic/anti-mycotic cocktails containing $10 \mathrm{mg} / \mathrm{ml}$ streptomycin, 10,000 U/ml penicillin as well as $25 \mu \mathrm{g} / \mathrm{ml}$ amphotericin B dissolved in $0.9 \% \mathrm{NaCl}$ solution, were also procured from Sigma-Aldrich. The 6-, 12- and 48-well plates used in the present study were obtained from Corning, Inc. (Corning, NY, USA).

Experimental protocol. Male Sprague-Dawley (SD) rats $(\mathrm{n}=150$; weight, $250-300 \mathrm{~g})$ were acquired from the National Laboratory Animal Center, Hospital of Taishan Medical College (Taishan, China). The rats were housed independently in cages at $25 \pm 1^{\circ} \mathrm{C}$, with access to food pellets and water ad libitum. A period of 7 days was allowed for the acclimatization of the rats. The in vivo work is reported in accordance with the Animal Research: Reporting of In Vivo Experiments guidelines (31). The present study was approved by the Ethics Committee of Taishan Medical College.

Induction of burn injuries and administration of treatment. Administration of AE and MA and the production of burn wounds was performed as previously described $(32,33)$. Prior to the production of the lesion, the SD rats were anesthetized by intraperitoneal injection with sodium pentobarbital $(60 \mathrm{mg} / \mathrm{kg}$ body; Sigma-Aldrich). By using lower portions of scapula, the back regions of the animals were then shaved and depilated. Subsequently, a burn wound of partial thickness was created by placing a $3.5 \times 4.6-\mathrm{cm}$ hot plate $\left(75^{\circ} \mathrm{C}\right)$ on the targeted location for $10 \mathrm{sec}$, and $\sim 10 \%$ of the entire body surface region was targeted for this purpose. Upon wound induction, $500 \mu \mathrm{l}$ test compound (MA or AE) was applied topically to the wound once daily. Using millimeter-scale graph paper, the wound injury was examined every 2 days, on days 2, 8, 10 and 14 . Upon reaching the end of the assessment period, the SD rats were sacrificed by overdose with sodium pentobarbital (intraperitoneal injection; $100 \mathrm{mg} / \mathrm{kg}$ body weight). For the purpose of histological examination, the tissues of healed wounds with dimensions $0.5 \times 0.5 \mathrm{~cm}$ were obtained from individual rats based upon their respective groups. For the control group, a topical application of Vaseline (Sigma-Aldrich) alone was performed.

Burn wound evaluation. Upon burn injury induction, the wounds were assessed grossly on days 2, 8, 10 and 14. The following parameters were assessed: Swelling of the wound surface and wound bed, the presence of exudates and coloration and consistency of the tissues surrounding the wounds.

Assessment of the degree of healing of burn injuries. After the induction of burn injuries, color images of lesions were obtained on days 2, 8, 10 and 14 post-treatment using a digital camera. Using a permanent marker pen and millimeter-scale transparent graph paper, the wound dimensions were tentatively measured and accordingly sketched on the trace paper. With the data collected, the wound healing properties were numerated by utilizing the following formula:

Degree of wound healing $(\%)=1$-[wound area on the corresponding day $\left(\mathrm{cm}^{2}\right) /$ wound area on day zero $\left.\left(\mathrm{cm}^{2}\right)\right]$ x 100

Histopathological examination of burn injuries. Tissue specimens with dimensions of $0.5 \times 0.5 \mathrm{~cm}$ were isolated from the burnt area at the midriff sections. The tissues were then kept in freshly prepared, neutral buffered solution with $10 \%$ formaldehyde for a period of $24 \mathrm{~h}$. Next, staining using hematoxylin and eosin were performed on the sections and further analyzed under a light microscope (Nikon 516609; Nikon Corporation, Tokyo, Japan) at objective magnifications of x 20 and x 40 .

Cells. The human acute monocytic leukemia cell line (THP-1) was procured from American Type Culture Collection (Manassas, VA, USA) and cultured in RPMI-1640 basal medium with supplementations of $10 \%$ fetal bovine serum (Thermo Fisher Scientific, Inc.), penicillin (100 U/cc), streptomycin $(100 \mu \mathrm{g} / \mathrm{ml})$ and amphotericin $(0.25 \mu \mathrm{g} / \mathrm{ml})$.

Determination of cell proliferation by 3-(4,5-dimethylthiazol-2-yl)-2,5-diphenyltetrazolium bromide (MTT) assay. For the quantification of cell proliferation and viability, an MTT assay was performed (Sigma-Aldrich) according to the manufacturer's protocol. In the assay, typically only viable cells 
Table I. Degree of wound healing of partial-thickness burn wounds treated with asiaticoside and madecassoside.

Degree of wound healing $(\%)$

\begin{tabular}{lcccc}
\cline { 2 - 4 } Group & Day 2 & Day 8 & Day 10 & Day 14 \\
\hline Untreated & $9.23 \pm 1.33$ & $15.23 \pm 2.19$ & $24.48 \pm 0.12$ & $28 \pm 2.3$ \\
Vaseline & $12.85 \pm 2.73$ & $19.34 \pm 0.23$ & $27.76 \pm 2.72$ & $39 \pm 1.38$ \\
Asiaticoside & $15.24 \pm 2.73$ & $28.62 \pm 1.21$ & $38.34 \pm 1.4^{\mathrm{a}}$ & $51.7 \pm 2.44^{\mathrm{b}}$ \\
Madecassoside & $11.71 \pm 1.47^{\mathrm{a}}$ & $22.81 \pm 1.37^{\mathrm{a}}$ & $28.25 \pm 1.011^{\mathrm{a}}$ & $73.1 \pm 1.51^{\mathrm{b}}$
\end{tabular}

Values are presented as the mean \pm standard error of the mean; $n=8 ;{ }^{a} \mathrm{P}<0.05$ and ${ }^{\mathrm{b}} \mathrm{P}<0.01$ vs. Vaseline group.

$\mathbf{A}$

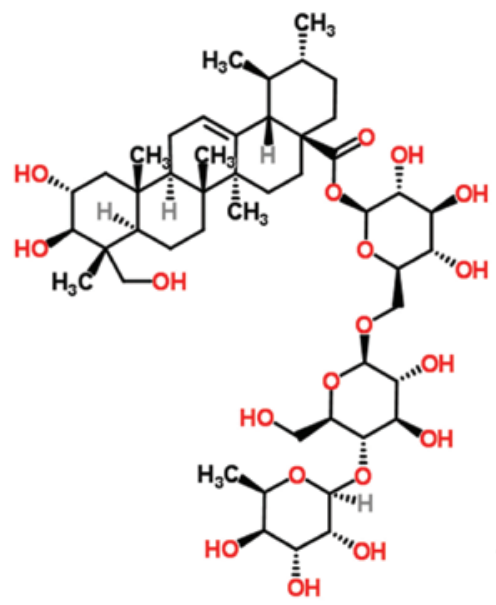

B<smiles>CC1CCC2(C(=O)OC3OC(COC4OC(CO)C(OC5OC(C)C(O)C(O)C5O)C(O)C4O)C(O)C(O)C3O)CCC3(C)C(=CCC4C5(C)CC(O)C(O)C(CO)(CO)C5C(C)CC43C)C2C1O</smiles>

Figure 1. Chemical structure of (A) asiaticoside and (B) madecassoside.

reduce MTT into insoluble purple formazan and the intensity of purple color directly correlates to the number of viable cells. The THP-1 cells were cultured on 96-well microtiter plate with seeding density of $5 \times 10^{3}$ cells/well containing $100 \mu \mathrm{l}$ RPMI media for a period of $48 \mathrm{~h}$. The media was changed after $48 \mathrm{~h}$ and replaced with basal media supplemented with various concentrations of MA and AE: 1,000, 500, 250, 125, $62.5,31.2,15.6$ and $7.8 \mathrm{ppm}$. The cells were then incubated in a humidified chamber with an atmosphere of $5 \% \mathrm{CO}_{2}$ at $37^{\circ} \mathrm{C}$. Media was replaced as required. Evaluation of viable cells was initiated by the addition of $100 \mu \mathrm{l}$ MTT solution into each well and incubating at $37^{\circ} \mathrm{C}$ in the dark for $4 \mathrm{~h}$. Crystals formed during the incubation period were then dissolved using $100 \mu \mathrm{l}$ of MTT organic solvent (prepared in $0.1 \mathrm{~N} \mathrm{HCl}$ dissolved in anhydrous isopropanol). Subsequently, optical density was
Table II. Effects of asiaticoside and madecassoside on VEGF and MCP-1 production in THP-1 cells on day 7 post-treatment.

\begin{tabular}{lcc}
\hline $\begin{array}{l}\text { Treatment } \\
\text { (per ml) }\end{array}$ & $\begin{array}{c}\text { VEGF } \\
(\mathrm{pg} / \text { well })\end{array}$ & $\begin{array}{c}\text { MCP-1 } \\
(\mathrm{ng} / \text { well })\end{array}$ \\
\hline $\begin{array}{l}\text { Asiaticoside } \\
0\end{array}$ & & \\
$10 \mathrm{pg}$ & $88.24 \pm 2.41$ & $2.11 \pm 0.32$ \\
$10 \mathrm{ng}$ & $95.23 \pm 0.11$ & $3.51 \pm 1.13^{\mathrm{a}}$ \\
$100 \mathrm{ng}$ & $97.23 \pm 1.14$ & $3.91 \pm 2.1^{\mathrm{a}}$ \\
Madecassoside & $98.35 \pm 0.134$ & $3.52 \pm 2.51$ \\
0 & & \\
$10 \mathrm{pg}$ & $89.14 \pm 1.31$ & $1.14 \pm 0.32$ \\
$10 \mathrm{ng}$ & $93.13 \pm 0.12$ & $2.55 \pm 1.23^{\mathrm{a}}$ \\
$100 \mathrm{ng}$ & $98.63 \pm 1.16$ & $3.91 \pm 1.12^{\mathrm{a}}$ \\
\end{tabular}

Values are presented as the mean \pm standard error of the mean; $n=6$; ${ }^{\text {aa }}<0.05$ vs. medium alone. VEGF, vascular endothelial growth factor; MCP-1, monocyte chemoattractant protein-1.

measured by means of an enzyme-linked immunosorbent assay (ELISA) reader, and was quantified at $570 \mathrm{~nm}$ with background subtraction at $690 \mathrm{~nm}(34,35)$. This was performed on days 1,4 and 7 post-treatment.

Quantification of vascular endothelial growth factor (VEGF) and monocyte chemoattractant protein 1 (MCP-1) production in THP-1 cells. Seeding density of THP-1 cells were fixed at $2 \times 10^{5}$ cells/per well in $100-\mathrm{mm}$ culture plates and subsequently maintained for a period of $48 \mathrm{~h}$. Upon reaching $80 \%$ confluency, the cells were exposed to $10 \mathrm{pg} / \mathrm{ml}, 10 \mathrm{ng} / \mathrm{ml}$ or $100 \mathrm{ng} / \mathrm{ml} \mathrm{AE}$ or MA for $\leq 24 \mathrm{~h}$. The levels of VEGF and MCP- 1 were detected respectively using ELISA kits (R\&D Systems, Inc., Minneapolis, MN, USA), according to the manufacturer's protocol.

Statistical analysis. Data are presented as the mean \pm standard error of mean. Statistical analyses were performed using SPSS software, version 21 (IBM SPSS, Armonk, NY, USA). The differential expressions among experimental groups were assessed using one-way analysis of variance, followed by Fisher's least significant difference test. $\mathrm{P}<0.05$ was considered to indicate a statistically significant difference. 
A

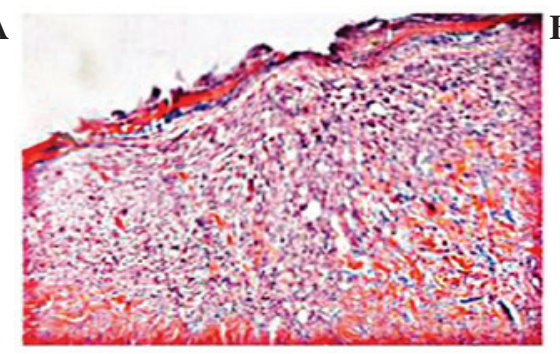

B

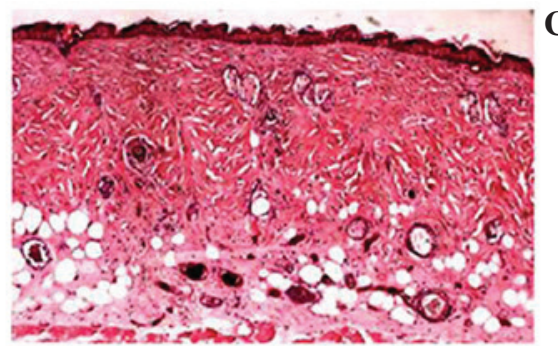

C

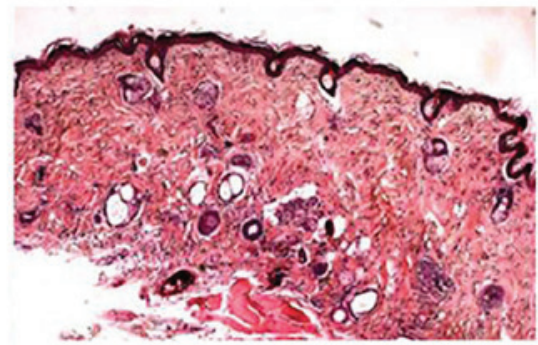

Figure 2. Histopathological evaluation of burn wounds treated with (A) Vaseline, (B) asiaticoside or (C) madecassoside on day 14 following injury.

A

$A$

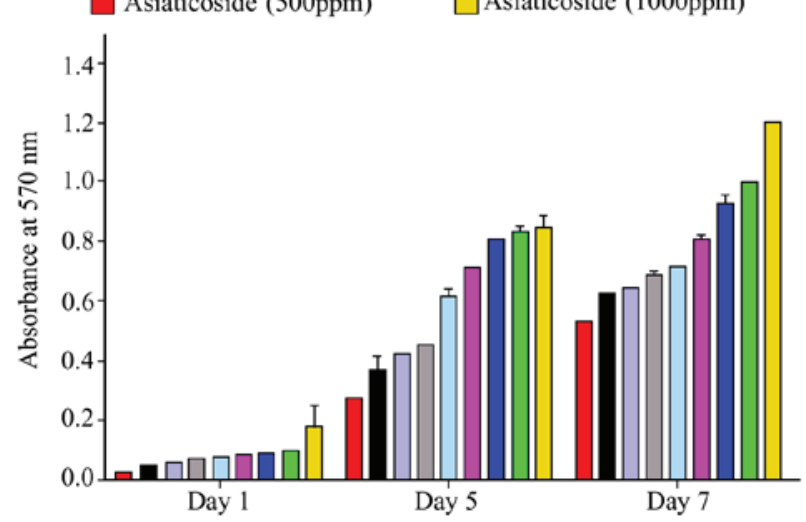

B
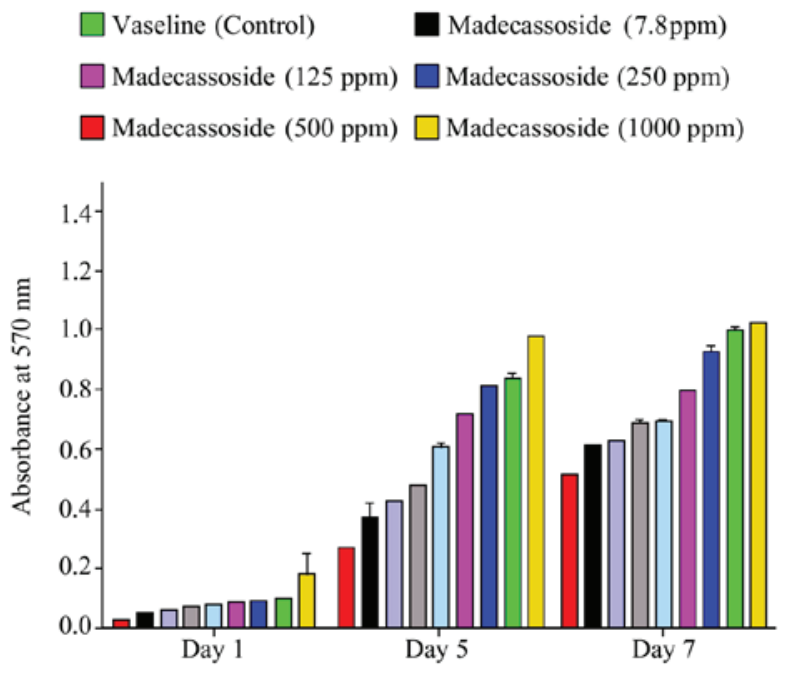

Figure 3. Effects of asiaticoside and madecassoside on THP-1 cell proliferation. The THP-1 cells were cultured with various concentrations $(1,000,500,250,125,62.5,31.2,15.6$ and $7.8 \mathrm{ppm})$ of (A) asiaticoside and (B) madecassoside and the number of viable cells was quantified by 3-(4, 5-dimethylthiazol-2-yl])-2,5-diphenyltetrazolium bromide assay.

\section{Results}

Effects of AE and MA on healing of burn wounds burn wound lesions. Compounds AE and MA (Fig. 1) were applied to treat burn wounds established in a rat model of burn wound healing. Following day 2, it was noted that wounds in the untreated, Vaseline-control group were swollen and bruised. Conversely, a modest level of swelling were observed in all AE- and MA-treated groups. The majority of injuries in the
A

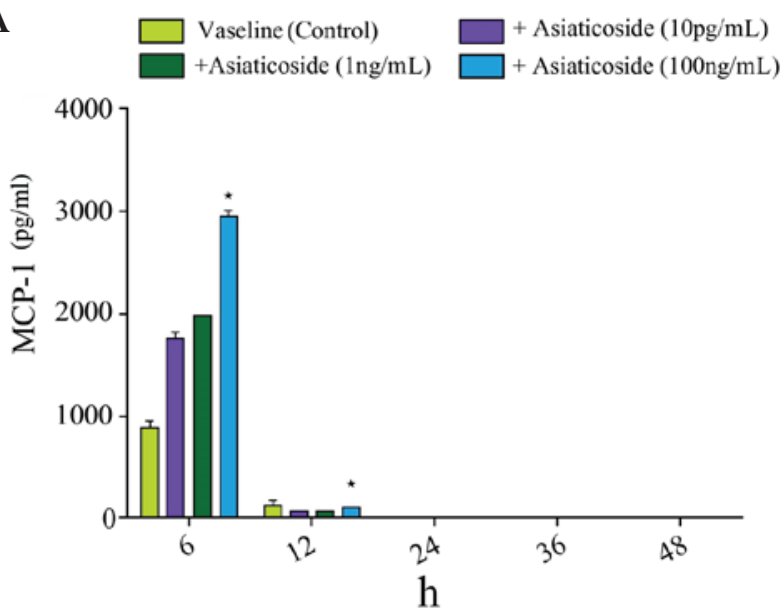

B $\quad \square$ Vaseline (Control) $\square$ Madecassoside (10 pg/mL) $\square$ Madecassoside (1 pg/mL)

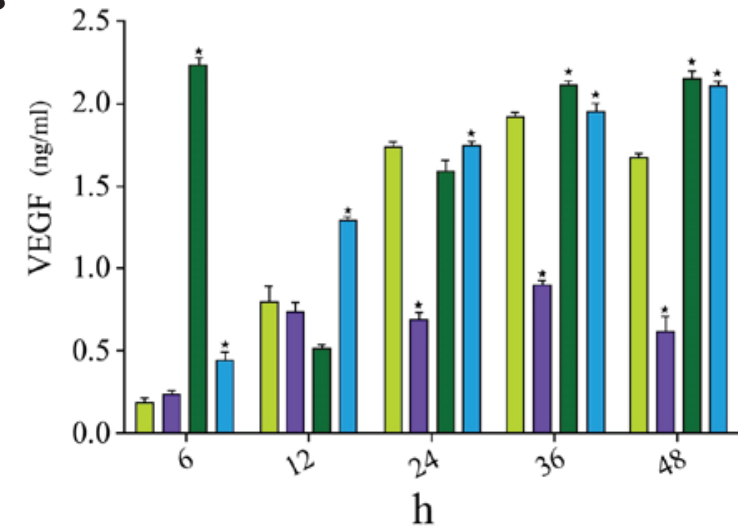

Figure 4. Effects of asiaticoside and madecassoside on THP-1 cells. Levels of (A) MCP-1 and (B) VEGF. "P<0.05 vs. control. MCP-1, monocyte chemoattractant protein-1; VEGF, vascular endothelial growth factor.

AE and MA groups began to heal and formed fibrous tissue. Notably, on day 8 the wounds in the untreated control, AE and MA groups were dark red in color, displayed wound size decrement at the injury site and remained unchanged in terms of physical magnitude. Wound contraction was also observed in all treatment groups compared with the control groups (data not shown).

The lesions in the AE- and MA-treated groups showed marked hair growth, and scabs were noted to be covering their respective lesion openings. Importantly, all wounds in the control, AE- and MA-treated groups exhibited a moderate level of exudation with no hair growth and scabs on top of lesion openings on day 10. Furthermore, the incidence of a dry 
surface, augmented hair development and progressive contraction of wound were noticeably present in all cases, in particular in the MA- and AE-treated groups. On the final day of the study (day 14), all burn wounds in the AE and MA groups, as well as the untreated group, exhibited marked levels of exudation and scab loss. In addition, increased hair formation was observed at the lesions in the AE- and MA-treated groups, which indicated that healing was taking place. Overall, the lesions in the AE- and MA-treated groups were significantly reduced in size after day 10 (Table I).

Histopathological assessment. On day 14, the control group displayed distinct fibrinoid necrosis in the subepidermal area, as demonstrated by the presence of collagen and fibrin, as well as evidence of degenerative changes. Furthermore, due to only minor skin outgrowth, re-epithelialization was not achieved and exudates were shown to cover the wound surface. Fibrinoid necrosis in selected areas of the subepidermis were noted, particularly in the wounds of the AE and MA groups. Furthermore, edema was detected in interstitial zone near the dermal region of the AE and MA groups. Re-epithelialization was incomplete; however, the lesions in the AE and MA groups appeared to be more severe compared with the control group (Fig. 2).

Cytotoxic properties of $A E$ and MA to THP-1 cells. The proliferation of THP-1 cells was measured following exposure to different concentrations of AE and MA at days 1, 4 and 7 post-treatment. Generally, it was observed that the cell viability increased in accordance with culture duration in all culture circumstances, except in cultures supplemented with 1,000 ppm AE and MA (Fig. 3). These results suggest that AE and MA at concentrations of $\leq 500 \mathrm{ppm}$ have no severe effects on the viability and proliferative ability of THP-1 cells in vitro. An anti-proliferative effect on THP-1 cells was only observed at the higher concentration of 1,000 ppm AE or MA (Fig. 3).

Effects of AE and MA on the production of VEGF and MCP-1 in THP-1 cells. As shown in Fig. 4, the levels of MCP-1 were significantly increased in THP-1 cells following treatment with $100 \mathrm{ng} / \mathrm{ml} \mathrm{AE}$ for 6 and $12 \mathrm{~h}(\mathrm{P}<0.05)$, as compared with the Vaseline-treated cells. After 12 h, MCP-1 expression became undetectable due to cell death leading to an insufficient number of cells. Furthermore, the levels of VEGF were significantly increased in THP-1 cells following treatment with $100 \mathrm{ng} / \mathrm{ml}$ MA for 6, 12, 24, 36 and $48 \mathrm{~h}(\mathrm{P}<0.05$; Fig. 4). However, the effect of MA and AE on VEGF production was not significant at day 7 post-treatment (Table II).

\section{Discussion}

Wound healing involves coordinating connective tissue repair, angiogenesis and re-epithelialization, in response to injury or trauma (36). The result is the formation of nascent tissue, fibroblast proliferation and the secretion of extracellular matrix proteins and growth factors $(27,37)$. It has been widely established that the role of angiogenesis is crucial during would healing. This process primarily supplies oxygen, as well as metabolites, to the newly formed tissues and works to remove any damaged and waste products of the metabolism during the repairing process (38). Furthermore, angiogenesis may be responsible for regulating processes involved in wound healing, indicated by the fact that impairment of angiogenesis causes wound healing to be impaired or unsuccessful (39). In addition, angiogenesis provides $60 \%$ of newly formed blood vessels with relevant repairing molecules and as such neovascularization would help in attaining normoxic conditions in hypoxic wounds (40).

Previous studies in the literature detail the effects of natural products sequestered from medicinal plants used for the purpose of skin regeneration, particularly in burn wound healing (41-43). In the present study, the burn wound healing properties of $\mathrm{AE}$ and $\mathrm{MA}$ were assessed using in vitro and in vivo experimental techniques. Cytotoxic assays confirmed the nontoxic nature of $\mathrm{AE}$ and $\mathrm{MA} \leq 500 \mathrm{ppm}$, however, the compounds displayed greater levels of toxicity at 1,000 ppm. The mechanisms underlying the action of AE and MA include the induction of collagen type I synthesis in human fibroblast cells of dermal origin through the phosphorylation of Smad 2 and Smad 3, and also fixation of Smad 3 onto Smad 4 (44). Studies have demonstrated the ability of AE to induce type I collagen by activating tumor formation via transforming growth factor $\beta$ receptor I kinase-independent Smad pathway $(45,46)$.

In the present study, it was revealed that $\mathrm{AE}$ and $\mathrm{MA}$ posses wound healing properties and are able to stimulate collagen synthesis, reducing wound oxidative stress as well as inducing vasodilatation. It was also indicated that $\mathrm{AE}$ and MA have positive effects on proliferation and cell growth in animal models. Previous studies have reported that these compounds may restore tissue functionality via activation of growth factors, including VEGF, endothelial growth factor and fibroblast growth factor $(22,25)$.

In conclusion, the present study highly supports the notion that $\mathrm{AE}$ and MA have potential benefits in would healing and may be potential agents in cases such as diabetes, thus warranting further studies.

\section{References}

1. Kowalske KJ: Burn wound care. Phys Med Rehabil Clin N Am 22: 213-227, 2011.

2. Murphy PS and Evans GR: Advances in wound healing: A review of current wound healing products. Plast Surg Int 2012: 190436, 2012.

3. Kartnig T: Clinical applications of Centella asiatica (L.) Urb. In: Herbs, Spices, and medicinal Plants: Recent Advances in Botany, Horticulture, and Pharmacology. Craker LE and Simon JE (eds). Vol 3. Oryx Press, Phoenix, pp145-173, 1986.

4. Penn JW, Grobbelaar AO and Rolfe KJ: The role of the TGF- $\beta$ family in wound healing, burns and scarring: A review. Int J Burns Trauma 2: 18-28, 2012.

5. Abu Kasim NH, Govindasamy V, Gnanasegaran N, Musa S, Pradeep PJ, Srijaya TC and Aziz ZA: Unique molecular signatures influencing the biological function and fate of post-natal stem cells isolated from different sources. J Tissue Eng Regen Med 9: E252-E266, 2015.

6. Hausen BM: Centella asiatica (Indian pennywort), an effective therapeutic but a weak sensitizer. Contact Dermat 29: 175-179, 1993.

7. Shukla A, Rasik AM and Dhawan BN: Asiaticoside-induced elevation of antioxidant levels in healing wounds. Phytother Res 13: 50-54, 1999.

8. Lu L, Ying K, Wei S, Liu Y, Lin H and Mao Y: Dermal fibroblast-associated gene induction by asiaticoside shown in vitro by DNA microarray analysis. Br J Dermatol 151: 571-578, 2004.

9. MacKay D and Miller AL: Nutritional support for wound healing. Altern Med Rev 8: 359-377, 2003. 
10. Heo DN, Yang DH, Lee JB, Bae MS, Kim JH, Moon SH, Chun HJ, Kim CH, Lim HN and Kwon IK: Burn-wound healing effect of gelatin/polyurethane nanofiber scaffold containing silver-sulfadiazine. J Biomed Nanotechnol 9: 511-515, 2013.

11. Haftek M, Mac-Mary S, Le Bitoux MA, Creidi P, Seité S, Rougier A and Humbert P: Clinical, biometric and structural evaluation of the long-term effects of a topical treatment with ascorbic acid and madecassoside in photoaged human skin. Exp Dermatol 17: 946-952, 2008

12. Kulac M, Aktas C, Tulubas F, Uygur R, Kanter M, Erboga M, Ceber M, Topcu B and Ozen OA: The effects of topical treatment with curcumin on burn wound healing in rats. J Mol Histol 44: 83-90, 2013.

13. Verbelen J, Hoeksema H, Heyneman A, Pirayesh A and Monstrey S: Aquacel(®) Ag dressing versus Acticoat ${ }^{\mathrm{TM}}$ dressing in partial thickness burns: A prospective, randomized, controlled study in 100 patients. Part 1: Burn wound healing. Burns 40: 416-427, 2014.

14. Gnanasegaran N, Govindasamy V and Abu Kasim NH Differentiation of stem cells derived from carious teeth into dopaminergic-like cells. Int Endodon J: Sep 9, 2015 (Epub ahead of print).

15. Soumyanath A, Zhong YP, Gold SA, Yu X, Koop DR, Bourdette D and Gold BG: Centella asiatica accelerates nerve regeneration upon oral administration and contains multiple active fractions increasing neurite elongation in-vitro. J Pharm Pharmacol 57: $1221-1229,2005$

16. Du J, Liu L, Lay F, Wang Q, Dou C, Zhang X, Hosseini SM, Simon A, Rees DJ, Ahmed AK, et al: Combination of HIF-1a gene transfection and HIF-1-activated bone marrow-derived angiogenic cell infusion improves burn wound healing in aged mice. Gene Ther 20: 1070-1076, 2013.

17. Osman A, Gnanasegaran N, Govindasamy V, Kathivaloo P, Wen AS, Musa S and Abu Kasim NH: Basal expression of growth-factor-associated genes in periodontal ligament stem cells reveals multiple distinctive pathways. Int Endod J 47: 639-651, 2014.

18. Hamed S, Bennett CL, Demiot C, Ullmann Y, Teot L and Desmoulière A: Erythropoietin, a novel repurposed drug: An innovative treatment for wound healing in patients with diabetes mellitus. Wound Repair Regen 22: 23-33, 2014.

19. Mahdavian Delavary B, van der Veer WM, van Egmond M, Niessen FB and Beelen RH: Macrophages in skin injury and repair. Immunobiology 216: 753-762, 2011.

20. Rigo C, Ferroni L, Tocco I, Roman M, Munivrana I, Gardin C, Cairns WR, Vindigni V, Azzena B, Barbante C and Zavan B: Active silver nanoparticles for wound healing. Int J Mol Sci 14 4817-4840, 2013

21. Yazid FB, Gnanasegaran N, Kunasekaran W, Govindasamy V and Musa S: Comparison of immunodulatory properties of dental pulp stem cells derived from healthy and inflamed teeth. Clin Oral Investig 18: 2103-2112, 2014.

22. Metcalf DG and Bowler PG: Biofilm delays wound healing: A review of the evidence. Burns Trauma 1: 5-12, 2015.

23. Mohamad N, Mohd Amin MC, Pandey M, Ahmad N and Rajab NF: Bacterial cellulose/acrylic acid hydrogel synthesized via electron beam irradiation: Accelerated burn wound healing in an animal model. Carbohydr Polym 114: 312-320, 2014.

24. Dumville JC and Munson C: Negative pressure wound therapy for partial-thickness burns. Cochrane Database Syst Rev 12 CD006215, 2012.

25. Stephen-Haynes J, Gibson E and Greenwood M: Chitosan: A natural solution for wound healing. J Comm Nurs 28: 48-53, 2014.

26. Barrientos S, Brem H, Stojadinovic O and Tomic-Canic M: Clinical application of growth factors and cytokines in wound healing. Wound Repair Regen 22: 569-578, 2014.

27. Singer AJ and Clark RA: Cutaneous wound healing. N Eng1 J Med 341: 738-746, 1999.
28. Aramwit P, Palapinyo S, Srichana T, Chottanapund S and Muangman P: Silk sericin ameliorates wound healing and its clinical efficacy in burn wounds. Arch Dermatol Res 305 585-594, 2013

29. Thakur R, Jain N, Pathak R and Sandhu SS: Practices in wound healing studies of plants. Evid Based Complement Alternat Med 2011: 438056, 2011.

30. Farzaei MH, Rahimi R, Abbasabadi Z and Abdollahi M: An evidence-based review on medicinal plants used for the treatment of peptic ulcer in traditional Iranian medicine. Int J Pharmacol 9: 108-124, 2013.

31. Kilkenny C, Browne WJ, Cuthill IC, Emerson M and Altman DG: Improving bioscience research reporting: The ARRIVE guidelines for reporting animal research. Osteoarthritis Cartilage 20: 256-260, 2012.

32. Zawacki BE: Reversal of capillary stasis and prevention of necrosis in burns. Ann Surg 180: 98-102, 1974

33. Somboonwong J, Thanamittramanee S, Jariyapongskul A and Patumraj S: Therapeutic effects of Aloe vera on cutaneous microcirculation and wound healing in second degree burn model in rats. J Med Assoc Thai 83: 417-425, 2000.

34. Mosmann T: Rapid colorimetric assay for cellular growth and survival: Application to proliferation and cytotoxicity assays. J Immunol Methods 65: 55-63, 1983.

35. Lee E and Surh YJ: Induction of apoptosis in HL-60 cells by pungent vanilloids, (6)-gingerol and (6)-paradol. Cancer Lett 134: 163-168, 1998.

36. Yao L, Li ZR, Su WR, Li YP, Lin ML, Zhang WX, Liu Y, Wan Q and Liang D: Role of mesenchymal stem cells on cornea wound healing induced by acute alkali burn. PLoS One 7: e30842, 2012.

37. Jettanacheawchankit S, Sasithanasate S, Sangvanich P, Banlunara W and Thunyakitpisal P: Acemannan stimulates gingival fibroblast proliferation; expressions of keratinocyte growth factor-1, vascular endothelial growth factor and type I collagen; and wound healing. J Pharmacol Sci 109: 525-531, 2009.

38. Greaves NS, Ashcroft KJ, Baguneid M and Bayat A: Current understanding of molecular and cellular mechanisms in fibroplasia and angiogenesis during acute wound healing. J Dermatol Sci 72: 206-217, 2013.

39. Moon EJ, Lee YM, Lee OH, Lee MJ, Lee SK, Chung MH, Park YI, Sung CK, Choi JS and Kim KW: A novel angiogenic factor derived from Aloe vera gel: Beta-sitosterol, a plant sterol. Angiogenesis 3: 117-123, 1999.

40. Ehrlich HP, Grislis G and Hunt TK: Metabolic and circulatory contributions to oxygen gradients in wounds. Surgery 72: 578-583, 1972.

41. Maenthaisong R, Chaiyakunapruk N, Niruntraporn S and Kongkaew C: The efficacy of Aloe vera used for burn wound healing: A systematic review. Burns 33: 713-718, 2007.

42. Ribeiro MP, Morgado PI, Miguel SP, Coutinho P and Correia IJ: Dextran-based hydrogel containing chitosan microparticles loaded with growth factors to be used in wound healing. Mater Sci Eng C 33: 2958-2966, 2013.

43. Cheppudira B, Fowler M, McGhee L, Greer A, Mares A, Petz L, Devore D, Loyd DR and Clifford JL: Curcumin: A novel therapeutic for burn pain and wound healing. Expert Opin Investig Drugs 22: 1295-1303, 2013.

44. Roy S, Elgharably H, Sinha M, Ganesh K, Chaney S, Mann E, MillerC,KhannaS, Bergdall VK, Powell HM, et al: Mixed-species biofilm compromises wound healing by disrupting epidermal barrier function. J Pathol 233: 331-343, 2014.

45. Lee J, Jung E, Kim Y, Park J, Park J, Hong S, Kim J, Hyun C, Kim YS and Park D: Asiaticoside induces human collagen I synthesis through TGFbeta receptor I kinase (TbetaRI kinase)-independent Smad signaling. Planta Med 72: 324-328, 2006.

46. Krausz AE, Adler BL, Cabral V, Navati M, Doerner J, Charafeddine RA, Chandra D, Liang H, Gunther L, Clendaniel A, et al: Curcumin-encapsulated nanoparticles as innovative antimicrobial and wound healing agent. Nanomedicine 11: 195-206, 2015. 